\title{
MICROENCAPSULATION OF OXOLINIC ACID WITH CHITOSAN BEADS
}

\author{
GALO CÁRDENAS-TRIVIÑO ${ }^{\prime *}$, MARIANELA BURGOS ${ }^{2}$, CARLOS von PLESSING ${ }^{3}$
}

\author{
${ }^{I}$ Facultad de Ingeniería, DIMAD, Centro de Biomateriales, Universidad del Bío-Bío, Av. Collao 1202, Concepción, CHILE \\ ${ }^{2}$ Facultad de Ciencias, Universidad Católica de la Santísima Concepción.mburgos@ucsc.cl \\ ${ }^{3}$ Departamento de Farmacia, Facultad de Farmacia, Universidad de Concepción, Chile.cvonples@udec.cl
}

\begin{abstract}
Chitosan microspheres were synthesized by the method of ionic gelling. The oxolinic acid was encapsulated in chitosan microspheres with different concentrations, which was corroborated by FT-IR of the spheres showing typical bands of chitosan and the antibiotic. The inclusion of antibiotic in the microspheres, was determined by means of thermogravimetry since there were two decompositions temperatures corresponding to different compounds. At several concentrations of oxolinic acid chitosan microspheres had different external morphology, by means of SEM was observed that a high concentration of antibiotic generated smooth external texture, where most of them were spherical shape.

The solubility of chitosan microspheres was very low in sea and nanopure water, since the protonation at basic $\mathrm{pH}$ of chitosan amino group was very low, the solubility was lower than diluted acetic acid. The solubility of chitosan at different concentrations of antibiotic microspheres showed a Gaussian tendency of solubility at different acid $\mathrm{pH}$ ranges (hydrogels). The optimum $\mathrm{pH}$ of chitosan spheres solubility occurred at $\mathrm{pH} 3.5$, which was observed at maximum point of curve. Chitosan microspheres had different concentrations of oxolinic acid, because releasing of antibiotic concentration may occur and which was measured by the HPLC method.

The percentage of encapsulation of microspheres was high, being all of them greater than $90 \%$. The release of oxolinic acid on chitosan microspheres was faster at $\mathrm{pH}$ 5.7, where the first releases were at 30 minutes after the test begins, instead at $\mathrm{pH} 7.5$ was slower.

Chitosan microspheres had an average dry weight of $1.1 \times 10^{-3} \mathrm{mg}$.
\end{abstract}

Keywords: microspheres, chitosan, oxolinic acid, morphology, concentration.

\section{INTRODUCTION}

Chile has around twenty five years of history in terms of salmon farming, time in which has made progress that have given it many economic benefits. However, these achievements are accompanied by the increase of several problems, such as the emergence of fish diseases. The main pathologies identified are generated mostly in the intensive culture of salmonid species, where the following bacteria associated to these diseases according to Smith [1] have been detected: Aeromonas salmonicida, Renibacterium salmoninarum, Yersinia ruckeri, Piscirickettsia salmonis detected in 1989, associated with the syndrome salmon rickettsial.

These four bacterial species have in common, the gram-negative property, where the main route of infection are the gills, also being either an entry way of these pathogens, the dissemination of them occurs mainly through the bloodstream of infected fish [1]

Piscirickettsia salmonis, has been so far the main cause of lost at fattening stage of the three species most important salmon in Chile, which correspond to the coho salmon, salmon trout and Atlantic Rainbow [2]. Piscirickettsia salmonis corresponds to the first isolated and characterized in fish rickettsia. This bacterium was initially isolated in Chile in 1989 by Fryer et al. [3] and Cvitanich et al. [4], from farming salmon affected by high mortality rates. This agent is a new species, which has been taxonomically classified in provisional form as a new genus and characterized as a bound intracellular pathogen, which multiplies by binary division, is cytopathic to different cell lines of salmonids, initially producing formation of clusters of rounded cells [3] and finally the lysis with detachment of the monolayer. Its optimal growth temperature is in the range of 15 to $18^{\circ} \mathrm{C}$, sharply reducing its growth under $10^{\circ} \mathrm{C}$ and $21^{\circ} \mathrm{C}$ [5]. In smears of blood and tissue, the rickettsias are stained with hematoxylineosin (HE), Giemsa and methylene blue, were observed within cytoplasmic vacuoles surrounded by a membrane, in scattered form or groupings that give an appearance of morula, as it is shown in Figure 1 [5].

The disease has been described mainly in seawater and estuarine and very occasionally in fresh water. The first outbreaks were related to a subsequent period of water temperature fluctuations, presence of non-toxic algae bloom, and/or stress [5]. Also is referred as Piscirickettsiosis disease, initially it was apparently specific for coho salmon, therefore the trend was to reduce the densities and increase Rainbow trout and Atlantic production of salmon. Facing this new situation, the disease was diagnosed increasingly in the last two species [5].

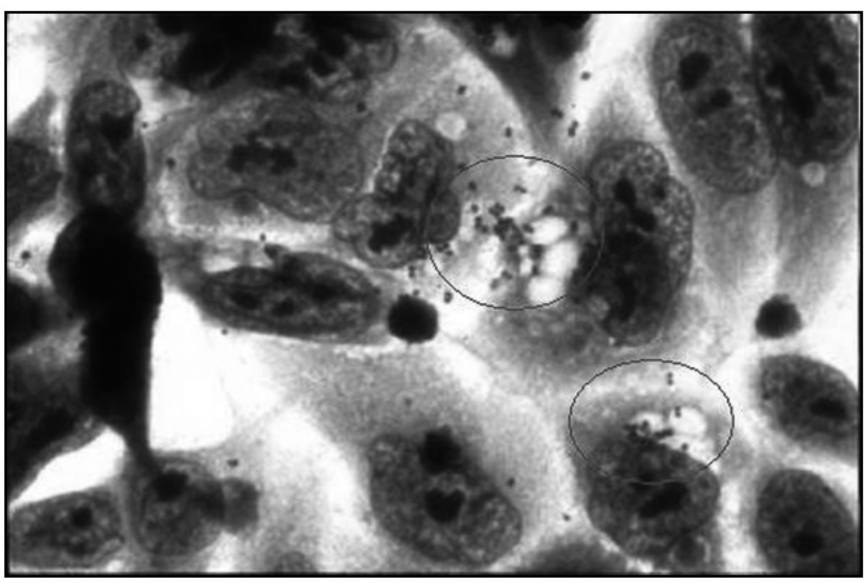

Figure 1. Culture cell infected (CHSE-214) with $P$. salmonis of the crop cells have cytoplasmic vacuoles in which the presence of microorganisms coccoidal is observed (demarcated in a circle) corresponding to P. salmonis.

The most relevant external macroscopic lesions includes: flaking, Gill pallor, ecchymotic hemorrhages and Petechial at the base of the fins, nodules and ulcers on the skin up to $2 \mathrm{~cm}$ in diameter. The necropsy analysis of the abdominal cavity, it is common to find presence of ascites, reno and splenomegaly, nodulation subcapsular from creamy color to beige in the liver, presence of a pseudo membrane on the heart and Petechial hemorrhages in the stomach, blind pilorics, gut, visceral fat, muscle, and swim bladder. In most of cases the intestine is filled with a yellowish mucus content and the stomach present transparent liquid seromucus, this last condition gives the impression that fish has swallowed water [6].

Chilean salmon farmers have also used different products to combat the pathologies associated to micro-organisms, such as antibiotics, chemotherapy and vaccine. Some antibiotics used are: oxolinic acid, clarithromycin, chloramphenicol, cotrimoxazole, erythromycin, spectinomycin, streptomycin, flumequine, furazolidone, gentamicin, oxytetracycline, penicillin, sarafloxacine, tetracycline [5].

Antibiotics have been used widely in cultures of salmon, particularly to control the rickettsial salmonid (SRS), associated to disease septicemia at Piscirickettsia salmonis, which represents $80 \%$ of the use of these antimicrobials [7]. 
Fryer et al. [4], determined that strain of Piscirickettsia salmons(LF-89) isolated from the first outbreaks of disease, showed a sensitivity to many antibiotics, being only resistant to penicillin. However, recent studies, have suggested a possible generation of resistance to several chemotherapeutic agents used as piscirickettsiosis treatment. A study by Palmer et al. [8], have shown an insulation resistance of a strain of North Ireland against cotrimoxazole, furazolidone and penicillin and sensitivity to oxolinic acid [5]

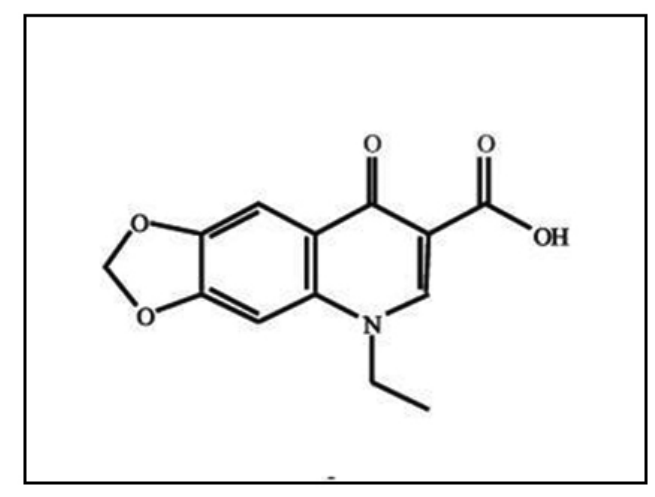

Figure 2. Structure of oxolinic acid (5-ethyl-5,8-dihydro-8-oxo-1,3-dioxol [4,5-g] quinolone-7-carboxilic acid)

The oxolinic acid, whose structure is shown in Figure 2, is a synthetic chemotherapeutic belonging to quinolones family of first generation as an amendment to nalidixic acid (first quinolone) synthesized in 1962. Quinolones have a chemical structure which consists of 2 rings, with one nitrogen at position 1, a Carbonyl in position 4 group and a carboxylic group in position 3 these having a common skeleton corresponding to 4-oxo-1, 4-dihidroquinoline. Oxolinic acid mechanism of action works by blocking DNA-gyrase bacterial, joining the subunit of type A. The bacteria has a special kind of type II topoisomerases, called gyrases, that introduce negative supercoiling in the double helix of DNA. DNA-gyrase is composed by two subunits of type A and two B-type $\left(\mathrm{A}_{2} \mathrm{~B}_{2}\right)$; Type $\mathrm{A}$ produces cut and successive double chain joints, while Type $B$ subunits are ATPases that provide energy to the reaction. The block of quinolones on the gyrase assumes that this is "frozen" in the phase in which the DNA is attached to the enzyme. This causes the accumulation of double-strand breaks, which leads to the death of the bacteria [9].

In relation to pharmacokinetics all quinolones have a good and quick absorption by mouth, binding to plasma proteins in a small percentage, less than $50 \%$ and are widely distributed in tissues and body fluids. Their elimination occurs primarily through the kidneys in more than $90 \%$ and the remainder is metabolized at liver level, producing (P-450) oxidation and conjugation [10].

Pure oxolinic acid, has a broad spectrum of action, which is aimed primarily at germs Gram negative and the administration corresponds to 10 to $30 \mathrm{mg} / \mathrm{kg}$ of fish per day.

Microencapsulate drug idea did not emerge until the mid-50s, when the pharmaceutical "Smith Kline and French" company introduced this technology in order to achieve a sustained or prolonged drug release. Late application of microencapsulation for medicinal products, became into a technology widely extended within pharmaceutical industry, in a short period time [11].

Microencapsulation benefits in drugs formulation according to Villa [11] could be summarized as follow:

- $\quad$ Reduction of the direct irritant effect caused by some medicines in the gastric mucosa. Examples of this are acid drugs character, being a singular case the aspirin.

- Masking the odor and flavor. Medication coating of undesirable organoleptic characteristics by a material that makes evident these features brings, without doubt, important advantages from the point of acceptability by the patient.

- Releasing in a sustained and controlled way an active ingredient from pharmaceutical formula. This is, at present, the most frequent application of microencapsulation.

The variety of materials that can be used in microencapsulation is being gradually extended, emerging new biomaterials and new applications. In general, is able to use micro materials that are classified into three categories: fats, proteins and polymers.

There are several methods of synthesis such as: coacervation, interfacial polymerization, extraction with evaporation of the solvent, spray and atomization-freezing, suspended in air and ionic gelling.

The main goal of this work was to get a high effectiveness in the administration of antibiotic within salmon farms in order to decrease the elevated amount used during the different growing stages.

\section{MATERIALS AND METHODS}

\section{Production of Chitosan}

Chitosan was obtained by the classical treatment with $\mathrm{NaOH} 45 \%$ w/w at $100^{\circ} \mathrm{C}$ from chitin of shrimps using the chemical method of $\mathrm{HCl}$ and $\mathrm{NaOH}$ The $10 \% \mathrm{w} / \mathrm{v}$ of $\mathrm{NaBH}_{4}$ addition, to the process reduces oxidation and achieve high molecular weights, preventing the depolymerization. All this stage must have a duration of 90 minutes. Once chitosan was obtained, it was washed with hot water to remove remaining $\mathrm{NaOH}$ and finally dried at room temperature.

Percentage of ashes in chitosan

The percentage of ash was determined through the method reported weighing dry chitosan sample in a porcelain crucible, previously placed in oven for $24 \mathrm{~h}$ at $900{ }^{\circ} \mathrm{C}$. The difference of weight gives the ashes percentage $[12,13]$.

Degree of deacetylation analysis

The determination of deacetylation degree using elemental analysis of nitrogen by the Kjeldahl method, relates the degree of acetylation (DA) with the percentage of nitrogen.

According to the following equation:

$$
\text { DA }(\%)=[(8,695-\% N) 1,799] * 100 \text {. }
$$

Where 8.695 is the percentage of nitrogen in the complete deacetylation of chitosan, 1.799 is the difference between 9.695 and 6.896 (percentage of $\mathrm{N}$ in chitin completely deacetylated) and $\% \mathrm{~N}$ is the percentage of $\mathrm{N}$ calculated on the organic fraction of the material analyzed [14].

Determination of molecular weight

Molecular weight of chitosan was determined using the viscosimetric method, by the equation of Mark-Houwink, which represents an empirical relationship between the average viscosimetric molecular weight and the intrinsic viscosity.

\section{Mark-Houwink equation: $(\mathbf{y})=\mathbf{K}\left(\mathbf{M}_{\mathrm{v}}\right)^{\mathrm{a}}$}

The Mark-Houwink parameters, $\mathrm{K}=0.074$ and $\mathrm{a}=0.76$ were used in a solvent system of $0.2 \mathrm{M} / 0.3 \mathrm{M}$ AcOH. The intrinsic viscosity $(\mathrm{y})$ in samples of chitosan was measured with an Ostwald viscometer at $25 \pm 0.5^{\circ} \mathrm{C}$ [13].

\section{Microencapsulation.}

The ionic gelling is a technique where microspheres cover formation takes place by a reaction of ionic gelling between an oppositely charged ion and a polysaccharide. Usually, sodium alginate gelation with calcium chloride (cation) are used. The method consists in suspending the compound that will be encapsulated in an aqueous solution of sodium alginate, adding the mixture by drip, on an aqueous solution of $\mathrm{CaCl}_{2}$ that is subject to adequate agitation speed. The contact drop of sodium alginate with $\mathrm{Ca}^{2+}$, produces an instant gelation of it, becoming into a membrane or coated calcium alginate that is insoluble in water but permeable. The reaction that takes place [11] is:

$$
2 \mathrm{Na} \text { - alginate }+\mathrm{Ca}^{2+} \rightarrow \mathrm{Ca}-\text { alginate }+2 \mathrm{Na}^{+}
$$

According to Rivas and co-workers [15] the characteristic analysis they usually performed to the microspheres were: i) morphological characteristics, particle size and internal structure ii) production performance and iii) effectiveness of encapsulation and active ingredient content. following the same principle, a chitosan solution was used.

\section{Content of oxolinic acid}

Content in active principle (AP) or capacity of encapsulation refers to the amount of drug encapsulated in the microspheres. The calculation was made by the following equation:

Content A.P. (\%) = encapsulated active ingredient quantity x 100 Final weight of microspheres

The performance or effectiveness of encapsulation (EE) was calculated from the relationship between the encapsulated active ingredient and the theoretical or able amount to be encapsulated. From the expression: 


\section{E.E. $(\%)=$ quantity of encapsulated active ingredient $\times 100$ Theoretical amount of active ingredient}

Release study of the active ingredient: As in other dosage forms of release-controlled, the studies release in vitro of the active molecule from the microspheres is very important. The release of active ingredient is governed by a series of factors that dependent on polymer, the active principle and own microsphere. Among those main factors the type of polymer (insoluble, soluble $\mathrm{pH}$ - dependent), its crystalline state and molecular weight. Parameters related to the active ingredient, include the same solubility and molecular weight. Finally, own microsphere dependent factors are, for example, type of internal structure (reservoir or matrix) and theoretical content of active ingredient with respect to polymer [16].

Preparation of chitosan microspheres

The synthesis of chitosan microspheres was carried out by ionic gelification, were the concentrated solution of chitosan $(5 \% \mathrm{w} / \mathrm{v})$ in acetic acid $1 \% \mathrm{v} / \mathrm{v}$ were dropped over KOH 0.5 M. Microspheres were produced fast, then filtered and washed with deionized water until neutral $\mathrm{pH}$, then they were left to dry in an oven with air convection at $40^{\circ} \mathrm{C}$.

Preparation of chitosan microspheres with oxolinic acid

To obtain the encapsulated oxolinic acid in Chitosan, a solution of oxolinic acid of $10 \mathrm{mg} / \mathrm{ml}$ in $\mathrm{NaOH} 0.03 \mathrm{M}$ was prepared and separately 6 Erlenmeyer flask were prepared with $20 \mathrm{ml}$ of Chitosan solution at $5 \%$ in acetic acid $2 \%$ and added different amounts of the solution of oxolinic acid (see table 2) and let them stirring for $12 \mathrm{~h}$. Then this solution was dropped, using the same procedure above.

The microspheres prepared were washed with hot water at neutral $\mathrm{pH}$ and then dried. There were samples between 1 and 10 milligrams of oxolinic acid. The KOH solution was saved for later HPLC analyses.

\section{SEM}

The samples, either microspheres with and without oxolinic acid were set up in the holder sample, Another samples were slized by half and being coated with gold sprayed of $150 \mathrm{~A}^{\circ}$ thickness. The equipment SEM ETEC Autoscan Model U-1 was used.

FTIR

The samples were prepared using $\mathrm{KBr}$ pellets with microspheres dried and grounded. Spectrograms were measured by FT-IR Nicolet Magna 550, provided with OMNIC program.

\section{Solubility tests}

Solubility was determined to different types of microspheres. The tests were carried out in sea water, nanopure water and $100 \mathrm{~mL} \mathrm{HCl} 1 \mathrm{M}$ at different $\mathrm{pH}(1,1.5,2,2.5,3,3.5,4,4.5,5$ and 5.5). Around $0.10 \mathrm{~g}$ of each microspheres were weighted and placed in beakers with $20 \mathrm{ml}$ of contact solution and then solutions were stirred, for sea water and nanopure water a 15 minutes period and $2 \mathrm{~h}$ for $\mathrm{HCl}$. Then the samples were dried in an oven at $40^{\circ} \mathrm{C}$ until constant weight, then final weight was registered and solubility was determined by difference.

Determination of oxolinic acid concentration in chitosan microspheres.

Concentration was measured by applying the method of linear regression, where a calibration curve was made, a HPLC method consisting of a Gemini column 3U C18 $3 \mu \mathrm{m}$ pore size of $4.6 \times 150 \mathrm{~mm}$ long, a mobile acid phase oxalic $0.01 \mathrm{M}(\mathrm{pH} 2.3)$ /Acetonitrile $(65: 35 \mathrm{v} / \mathrm{v})$, with a flow of $0.8 \mathrm{ml} / \mathrm{min}$ and a volume of $10 \mu \mathrm{l}$ injection; was carried out, during a period of 8 minutes. A fluorescence detector with a wavelength of $312 \mathrm{~nm}$ excitation and absorption of $368 \mathrm{~nm}$ was used to quantify. The equipment used was a Lachrom Elite with a L-2480 detector, L-2130 pump and L-2200 autosampler. The standards were prepared from a stock solution of $1000 \mu \mathrm{g} / \mathrm{ml}$ of oxolinic acid in $\mathrm{NaOH} 0.03 \mathrm{M}$, and they were prepared according to the following dilutions: $0.02,0.05,0.1$, $0.25,0.5,0.75,1$ and $2 \mu \mathrm{g} / \mathrm{mL}$. The dilutions were performed in $1 \mathrm{ml}$ Ependorff and then they were shaken in a mini shaker, each standard was filtered using Millex-GV with PVDE membrane $0.45 \mu \mathrm{m}$ pore size and $13 \mathrm{~mm}$ in diameter millipore and transferred to vials for subsequent injection into the equipment, with 5 calibration curves. Each standard curve was injected in triplicate and then an average among 5 curves was taken. Solutions of $\mathrm{KOH}$ were dropped into chitosan solutions with different concentrations of oxolinic acid being neutralized with $\mathrm{HCl} 0.1 \mathrm{~N}$ and it was taken from these $500 \mu \mathrm{L}$ and complete volume with $500 \mu \mathrm{L}$ of mobile phase. Then they were filtered in the same way as the standards, being injected in duplicate. The concentration of active in the $\mathrm{KOH}$ solution that would correspond to the loss could be determined from the supplied areas of acid oxolinic from microspheres and difference in relation to the initial antibiotic concentration determines the capability of encapsulation (E.C.), using the following formula:

\section{E.C. $(\%)=$ Number of encapsulated active ingredient $x 100$ Final weight of microspheres}

In addition, determines the effectiveness of encapsulation (E.E.) according to the following relationship:

\section{E.E. $(\%)=$ Number of encapsulated active ingredient $x 100$ Theoretical amount of active ingredient}

Study of release kinetics.

The basis for release kinetics theory of Fick's diffusion law it was used, where the dissemination in relationship was determined at time to the 6 concentrations tested, for this, it was weighed $0.2578 \mathrm{~g}$ of spheres approximately and placed in a glass precipitate on a metal mesh adapted under the level of maximum volume of the solution used for diffusion, so those areas only were contacted the solution but were not in continuous stirring, in order to keep a slow diffusion process. First, the test was performed using $60 \mathrm{~mL}$ phosphate buffer $\mathrm{pH} 5.7$ and remain in slow stirring for 16 hours. Samples of $1 \mathrm{~mL}$ were taken at: $0,30,60,90,120,180,240,300,600$ and 960 minutes. Then, again same amount of microspheres was weighed and placed in $60 \mathrm{~mL}$ of buffer phosphate $\mathrm{pH} 7.5$ and remained an average 54 hours stirring. Samples of $1 \mathrm{~mL}$ were taken at: $0,0.5,1,1.5,2,2.5,3,8,45$ and 54 hours. Then, the samples were filtered and analyzed by HPLC. The $\mathrm{pH}$ chosen from testing of release was $\mathrm{pH}$ 5.7, which simulates the $\mathrm{pH}$ within fish body and $\mathrm{pH} 7.5$, which simulates $\mathrm{pH}$ in aquatic environment. [17]

Extraction tests. Trials of extraction for the 6 concentrations tested, were conducted in order to determine the concentration of oxolinic acid encapsulated into microspheres. Chitosan microspheres were grounded carefully in a mortar and $1 \mathrm{ml}$ of $\mathrm{NaOH} 0.03 \mathrm{M}$ was added, then agitated for $10 \mathrm{~min}$ in a minishaker, this procedure was followed with 5 samples for each concentration which dispersion were then filtered and injected into the liquid chromatograph to determine its concentration. [17]

Preliminary tests

Preliminary tests were carried out in the bioassays laboratories of Faculty of Biology at Universidad de Concepción. To determine microspheres toxicity, several oral toxicity tests were performed using four different methodologies, testing in the following species of fish: Cheirodongalusdae, Oncorhynchus mykiss (rainbow trout), Salmo salar (Atlantic salmon), Gambusiaaffinis (mosquito fish).

Methodology 1: Cheirodongalusdae taken from an aquarium and were stacked in the container where a known quantity of microspheres was thrown off to them then next day the quantity ingested by fishes was checked.

Methodology 2: Chitosan microspheres were covered one at time with a base of fish food paste and were given to Gambusiaaffinis and Oncorhynchus mykiss that were placed in separate containers. The next day chitosan microspheres amount ingested by fish was checked.

Methodology 3: Chitosan solution 5\% $(10 \mathrm{ml})$ it was mixed with $50 \mathrm{ml}$ fish oil and dripped on a solution of $\mathrm{KOH} 0.5 \mathrm{M}$. Formed spheres were washed, dried, and were given to Salmo salar, Cheirodongalusdae and Gambusiaaffinis, which were placed in separate containers. Next day, amount ingested by fish was checked.

Methodology 4: a small amount of pellets was ground and then mixed with chitosan solution $6 \%$ and dripped on a solution of $0.5 \mathrm{M} \mathrm{NaOH}$. Spheres obtained, were washed and withdrew a percentage of moisture in the stove. They were given to the fish before spheres were completely dried, fish that were tested: Salmo salar, Cheirodongalusdae and Gambusiaaffinis. Next day it was registered the amount ingested by fish.

\section{RESULTS AND DISCUSSION}

Chitosan used was obtained from red prawn shells, their characterization is summarized in table 1 , in the case of viscosity $[12,13]$ and nitrogen, both values were in the range characteristic of chitosan.

Table 1. Report of the characterization of chitosan, obtained from red prawn shells.

\begin{tabular}{|c|c|c|c|c|c|}
\hline Sample & $\begin{array}{c}\text { Ash } \\
(\%)\end{array}$ & $\begin{array}{c}\text { Molecular } \\
\text { Weight (g/ } \\
\text { mol) }\end{array}$ & $\begin{array}{c}\text { Degree } \\
\text { deacetylation } \\
(\%)\end{array}$ & $\begin{array}{c}\text { Viscosity } \\
(\mathrm{cps})\end{array}$ & $\begin{array}{c}\text { Nitrogen } \\
(\%)\end{array}$ \\
\hline Chitosan & 0.3 & 97500 & 95 & 104 & 8.2 \\
\hline
\end{tabular}


Most of the procedures of micro encapsulation imply an intimate mixing between the polymer and the active ingredient, so it can have place differen physico-chemical interactions affecting the therapeutic efficacy of the final dosage form. Consequently, it is convenient to characterize the physical state of polymer and active ingredient separately, and the active principle in the microsphere (active ingredient dissolved or dispersed in polymer), also highlight the possible existence of interactions drug - excipient.

\section{PREPARATION OF CHITOSAN SPHERES}

Due to the poly cationic chitosan nature, it has been prepared a series of poly complexes which have characteristics of hydrogels, the reason why it has been possible to study them in the controlled release of drugs, including anticancer treatments complex polyelectrolyte type that encapsulates a concentrated solution of a polyelectrolyte into a skin, formed by the electrostatic interaction of the polymer with another of opposite charge. Microspheres obtained by any of the procedures described must be characterized and controlled in accordance with tests that ensure their quality and homogeneity, as well as its biopharmaceutical behavior.

Table 2. Oxolinic acid concentration in microspheres.

\begin{tabular}{|c|c|c|c|c|c|}
\hline Beaker & $\begin{array}{c}\text { Chitosan } \\
\text { solution(mL) }\end{array}$ & $\begin{array}{c}\text { Chitosan } \\
(\mathrm{g})\end{array}$ & $\begin{array}{c}\text { Oxolinic } \\
\text { acid } \\
\text { solution } \\
(\mathrm{mL})\end{array}$ & $\begin{array}{c}\text { Oxolinic } \\
\text { acid (mg) }\end{array}$ & $\begin{array}{c}\text { KOH 0.5 } \\
\text { M (mL) }\end{array}$ \\
\hline 1 & 20 & 1.2 & 2 & 2 & 20 \\
\hline 2 & 20 & 1.2 & 3 & 3 & 20 \\
\hline 3 & 20 & 1.2 & 4 & 4 & 20 \\
\hline 4 & 20 & 1.2 & 5 & 5 & 20 \\
\hline 5 & 20 & 1.2 & 6 & 6 & 20 \\
\hline 6 & 20 & 1.2 & 7 & 7 & 20 \\
\hline
\end{tabular}

CHARACTERIZATION OF CHITOSAN MICROSPHERES [16]

Synthesis of Chitosan microspheres with oxolinic acid. Formation of microspheres takes place by means of a gelation reaction, where chitosan solubilized with acetic acid by protonation of the amino group. This system behaves as a polycation which get in contact with $\mathrm{KOH}$ (anion) gives rise to a polyelectrolyte reaction by difference of loads where the outer layer of the chitosan solution precipitates as chitosan gel. The reaction proposed for gelation of chitosan in $\mathrm{KOH}$ reaction is shown below.

Figure 3 shows a proposed model for the formation of chitosan with oxolinic acid microspheres, where the outer layer of microspheres gels to be in contact the $\mathrm{KOH}$ solution, on the inside, here is where the solution of chitosan (not gelled) containing antibiotic (see figure 3, blue little squares)

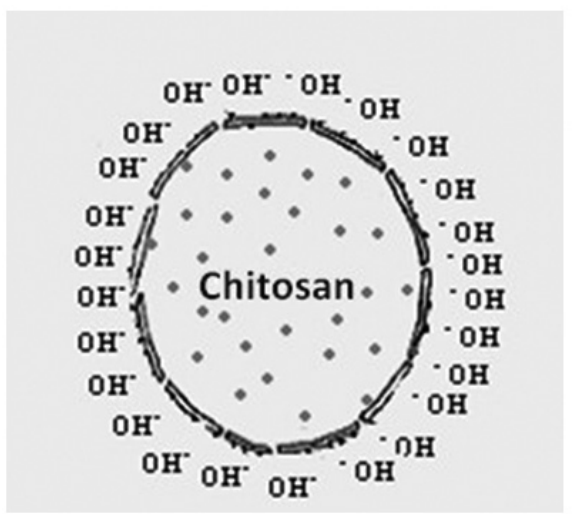

Figure 3. Model proposed for the gelling of oxolinic acid microspheres.

\section{(FT-IR) spectroscopy}

The FT-IR absorption spectrum in the middle region of chitosan microspheres was registered (Figure 4$)$. The first band corresponds to the stretching $(\bar{v}-\mathrm{OH})$ at 3431 then at $2878 \mathrm{~cm}^{-1}(\bar{v} \mathrm{C}-\mathrm{H})$. The acetamide of chitin shows an absorption band at $1655 \mathrm{~cm}^{-1}$. The $1381 \mathrm{~cm}^{-1}$ signal correspond to deformation of the $\mathrm{NH}_{2}$ group. The $\bar{v} \mathrm{C}-\mathrm{O}$ bond has a vibration of tension at $1085 \mathrm{~cm}^{-1}$ and the $\mathrm{N}-\mathrm{H}$ group deformation at $590 \mathrm{~cm}^{-1}$ is observed [18].

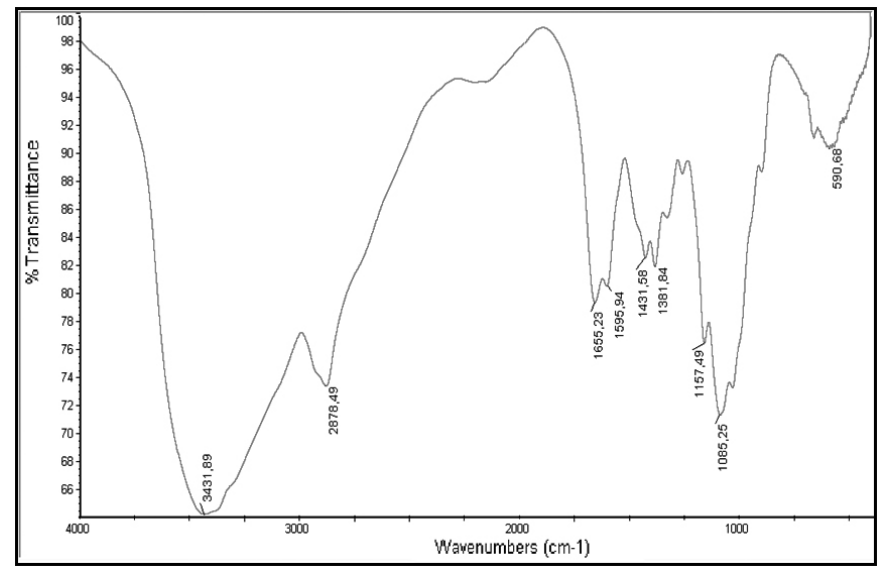

Figura 4.- FT-IR of chitosan microspheres.

The FT-IR spectrum of oxolinic acid (Figure 5) displayed, the first band at $3401 \mathrm{~cm}^{-1}$ corresponds to the stretching vibration of the $-\mathrm{OH}$ group, then 3-band characteristics of heterocyclic compounds are between $3061 \mathrm{~cm}^{-1}$ and $2927 \mathrm{~cm}^{-1}$. The stretching vibration of $\mathrm{C}=\mathrm{O}$ of the carboxylic group presents a band at $1705 \mathrm{~cm}^{-1}$. The $\mathrm{C}=\mathrm{C}$ bond of the quinolinic ring shows an absorption at $1448 \mathrm{~cm}^{-1}$. At $1570 \mathrm{~cm}^{-1}$ presents a vibration $\mathrm{C}=\mathrm{O}$ or the ketone carbonyl group. The $\mathrm{C}=\mathrm{N}$ group of the quinoline is presented at $1448 \mathrm{~cm}^{-1}$ and $938 \mathrm{~cm}^{-1}$ the absorption band of acetal group.

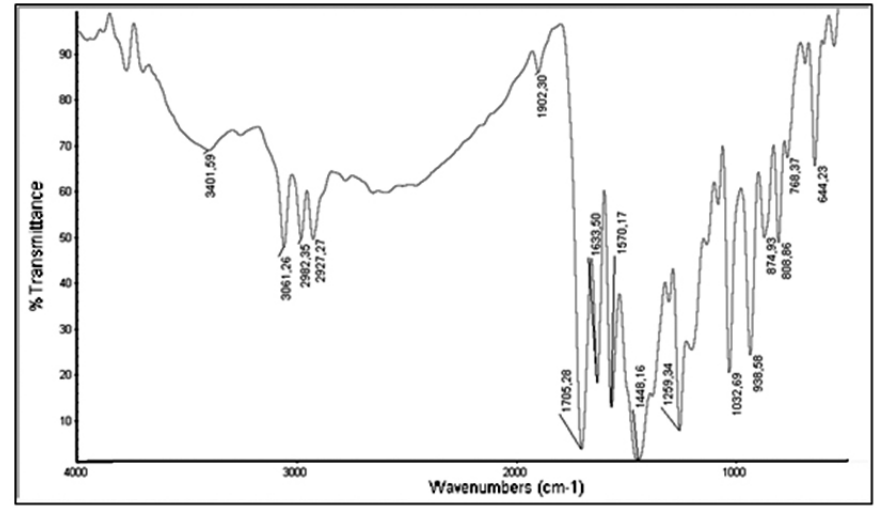

Figure 5. FT-IR of oxolinic acid.

Table 3 shows the summary of FT-IR absorbance bands of greater importance which indicated presence of characteristic bands of chitosan and oxolinic acid in encapsulated microspheres. In the case of the encapsulated 6 , absorption bands were similar, therefore they had the same structure. The first band that appears at $3433 \mathrm{~cm}^{-1}$ corresponds to the stretching of the $-\mathrm{OH}$ from chitosan, then close to $1633 \mathrm{~cm}^{-1}$ appears a band corresponding to the vibration of oxolinic acid $\mathrm{C}=\mathrm{C}$ of quinolinic center ring. The stretching vibration of $\mathrm{C}=\mathrm{O}$ acetamide of chitosan present a band at $1564 \mathrm{~cm}^{-1}$. Vibration $\mathrm{C}=\mathrm{N}$ of the position 1 antibiotic appears at $1412 \mathrm{~cm}^{-1}$ for the encapsulated 6 and $\mathrm{C}-\mathrm{O}$ vibration, absorption band at $1089 \mathrm{~cm}^{-1}$. Either chitosan nor oxolinic acid, did not show characteristic bands of some functional groups, this was due to the overlap of bands that have a higher intensity compared to others, as the $-\mathrm{OH}$ vibration on chitosan, overlapped band are characteristic of the heterocyclic ring of antibiotic. 
Table 3. Table of the more important absorbance bands of chitosan spheres with oxolinic acid.

\begin{tabular}{|c|c|c|c|c|c|c|}
\hline Functional groups & \multicolumn{7}{|c|}{ Bands (cm $\left.{ }^{-1}\right)$} \\
\hline & $\mathbf{1}$ & $\mathbf{2}$ & $\mathbf{3}$ & $\mathbf{4}$ & $\mathbf{5}$ & $\mathbf{6}$ \\
\hline O-H & 3434.23 & 3439.27 & 3439.27 & 3431.74 & 3433.1 & 3433.1 \\
\hline C = C, quinoline & 1642.69 & 1633.28 & 1633.09 & 1637.89 & 1634.49 & 1633.14 \\
\hline Axial stretch C = O (amide 1) & 1556.13 & 1564.29 & 1556.18 & 1563.98 & 1551.54 & 1564.02 \\
\hline C = N, quinoline & 1413.46 & 1415.3 & 1413.06 & 1413.33 & 1412.36 & 1412.92 \\
\hline C-O vibration & 1087.19 & 1088.82 & 1023.93 & 1091.00 & 1093.18 & 1089.78 \\
\hline
\end{tabular}

\section{Thermogravimetric analysis (TGA)}

Results of scans, showed temperature in relation to the percentage of mass loss (green curve) and the first derivative of the relationship between the percentage of mass loss and temperature (blue curve). The termogravimetry reached a temperature of $600^{\circ} \mathrm{C}$ where the remnants of the curve were shown.

Figure 5 shows the thermogram for chitosan spheres, leaving a remnant of a $34.24 \%$ at $596{ }^{\circ} \mathrm{C}$ corresponding to carbonated chains. Table 3 summarizes decomposition temperatures (TD).

Chitosan microspheres exhibited a residual weight of $34.24 \%$ at $596.57^{\circ} \mathrm{C}$. Oxolinic acid presented a $\mathrm{TD}=596.7^{\circ} \mathrm{C}$ and a $57.35 \%$ of residual weight (Table 3). The scans for the encapsulated with different concentrations of antibiotics where its residues were $37 \%$, corresponding to the remnant that is left in the case of the chitosan samples. These scans showed also two peak in the first derivative which corresponded to the decomposition of two compounds, which indicated the presence of antibiotic in the encapsulated.

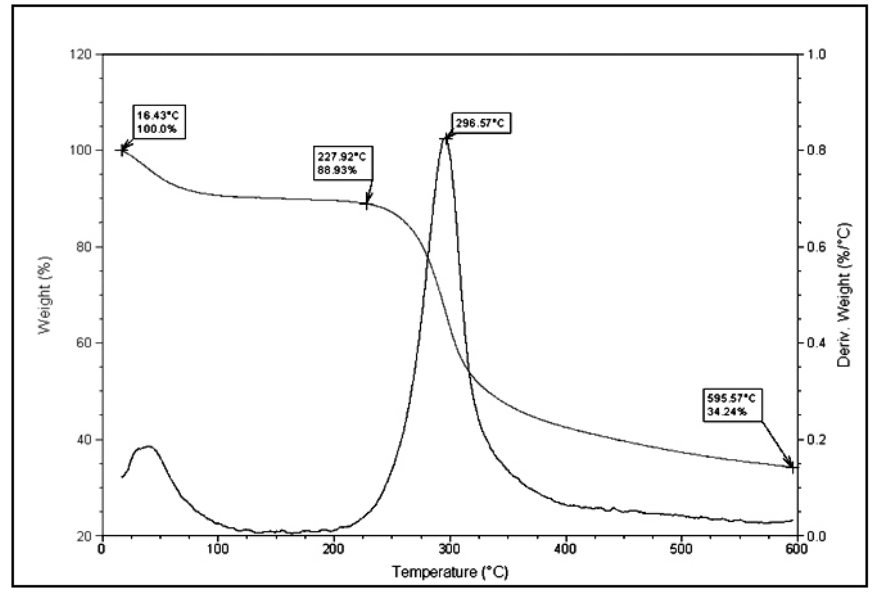

Figure 5. Thermogram of Chitosan spheres.

Figure 6 show the thermogram of pure oxolinic acid with a decomposition temperature $\left(\mathrm{TD} 1=324.79^{\circ} \mathrm{C}\right)$

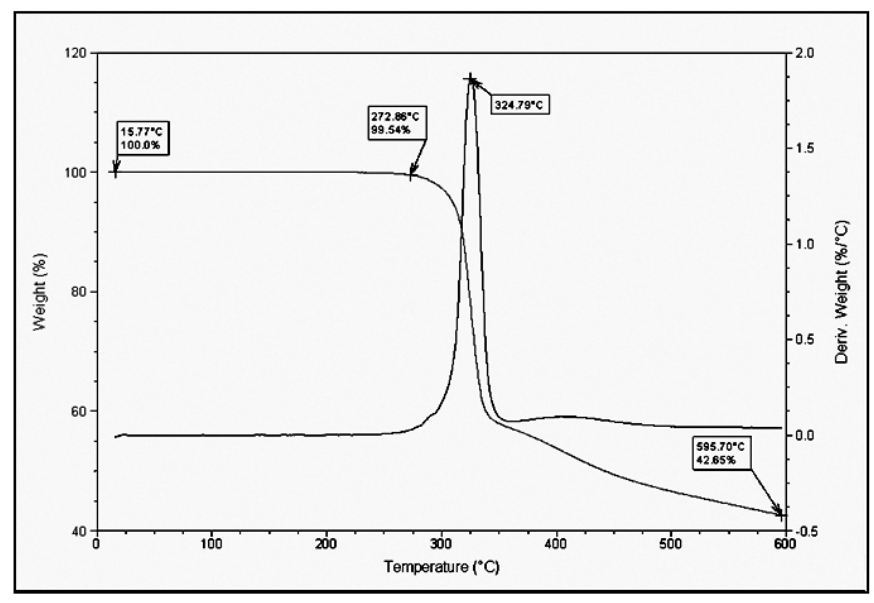

Figure 6. Thermogram of Oxolinic acid powder.
Figure 7 shows the thermogram of the chitosan microspheres with 6 mg of oxolinic acid incorporated with a decomposition temperature (TD1 = $\left.279.95^{\circ} \mathrm{C}\right)$.

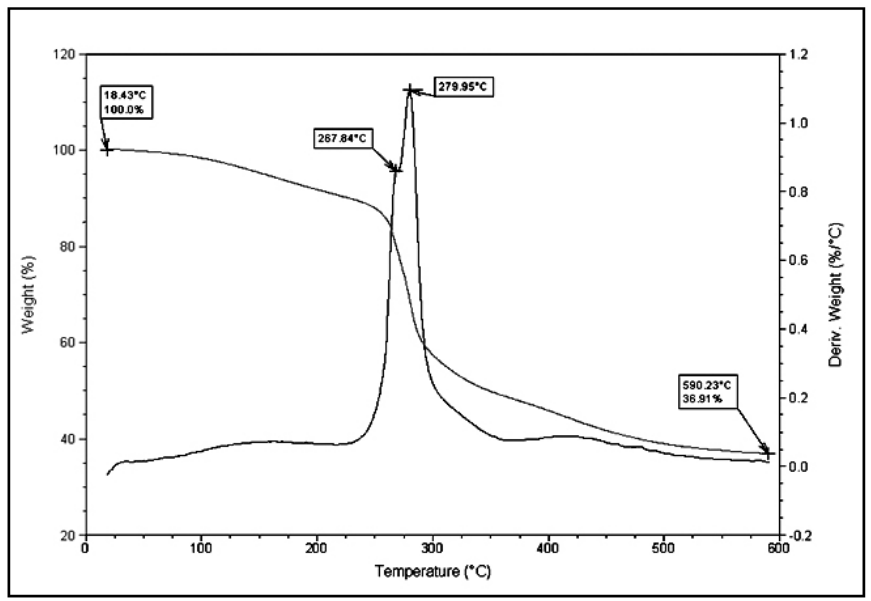

Figure 7. Thermogram of Chitosan spheres with oxolinic acid (sample 6)

Table 4 summarizes de decomposition temperatures of chitosan, oxolinic acid and spheres charged with oxolinic acid. The first decomposition temperature (TD1) for the microspheres was lower than pure chitosan and the temperature decreased along with the increase of oxolinic content. On the other hand, at final temperature, residual weight was quite similar ranging from 596 to $590^{\circ} \mathrm{C}$ and mass loss ranging from 57 to $68 \%$.

Table 4. Decomposition temperatures of microspheres.

\begin{tabular}{|cc|c|}
\hline Sample & TD1 & TD2 (mass loss (\%)) \\
\hline QS Microsphere & $\mathbf{2 9 6 . 5 7}$ & $596.57^{\circ} \mathrm{C}(66,63 \%)$ \\
\hline QS-Oxolinic Acid & $\mathbf{3 2 4 . 7 9}$ & $596.70^{\circ} \mathrm{C}(57,35 \%)$ \\
\hline $\mathbf{2}$ & $\mathbf{2 8 7 . 2 2}$ & $590.23^{\circ} \mathrm{C}(63,02 \%)$ \\
\hline $\mathbf{3}$ & $\mathbf{2 8 9 . 0 3}$ & $596.57^{\circ} \mathrm{C}(66,63 \%)$ \\
\hline $\mathbf{4}$ & $\mathbf{2 8 5 . 2 4}$ & $590.98^{\circ} \mathrm{C}(63,03 \%)$ \\
\hline $\mathbf{5}$ & $\mathbf{2 8 2 . 2 2}$ & $590.60^{\circ} \mathrm{C}(63,09 \%)$ \\
\hline $\mathbf{6}$ & $\mathbf{2 7 9 . 9 5}$ & $590.23^{\circ} \mathrm{C}(68,09 \%)$ \\
\hline
\end{tabular}

\section{Scanning electron microscopy (SEM)}

The scanning electron micrographs shows the images on the surface of the microspheres, Figure 6 shows each microspheres synthesized with different concentrations of oxolinic acid, also the relation to the increase in particle size was determined. The microspheres made with $2 \mathrm{mg}$ of antibiotic (6-a) showed a regular spherical shape, a surface with an irregular texture, and a particle size of $1.28 \mathrm{~mm}$ diameter. Figure 6-b correspond to the package with $3 \mathrm{mg}$ of antibiotic, has a similarly to the previous bead, spherical shape and irregular texture on its surface, its particle size was $1.41 \mathrm{~mm}$ in diameter. The synthesized microspheres with antibiotic $3 \mathrm{mg}$, shown on Figure 6-c and unlike other spheres has a ball-shaped elongated, due to a chitosan solution to the samples with oxolinic acid solution, diluted and to drip the solution, drop coming from syringe loses its drop shape by contact to change from 
one medium to another its surface shows the presence of salts. Salts presence correspond to the remains of $\mathrm{KOH}$ from neutralization by washing with water, its particle size was $1.06 \mathrm{~mm}$ in diameter. The microspheres synthesized with 4 mg antibiotic (Figure 6-d) has a regular spherical shape and a smooth surface, the surface depends on washing and concentration of chitosan solution, where the chitosan solution diluted makes surface smooth and when chitosan solution is concentrated makes compact microsphere with irregular surface, and particle size of $1.16 \mathrm{~mm}$ in diameter.

Microspheres synthesized with the highest concentrations of antibiotic
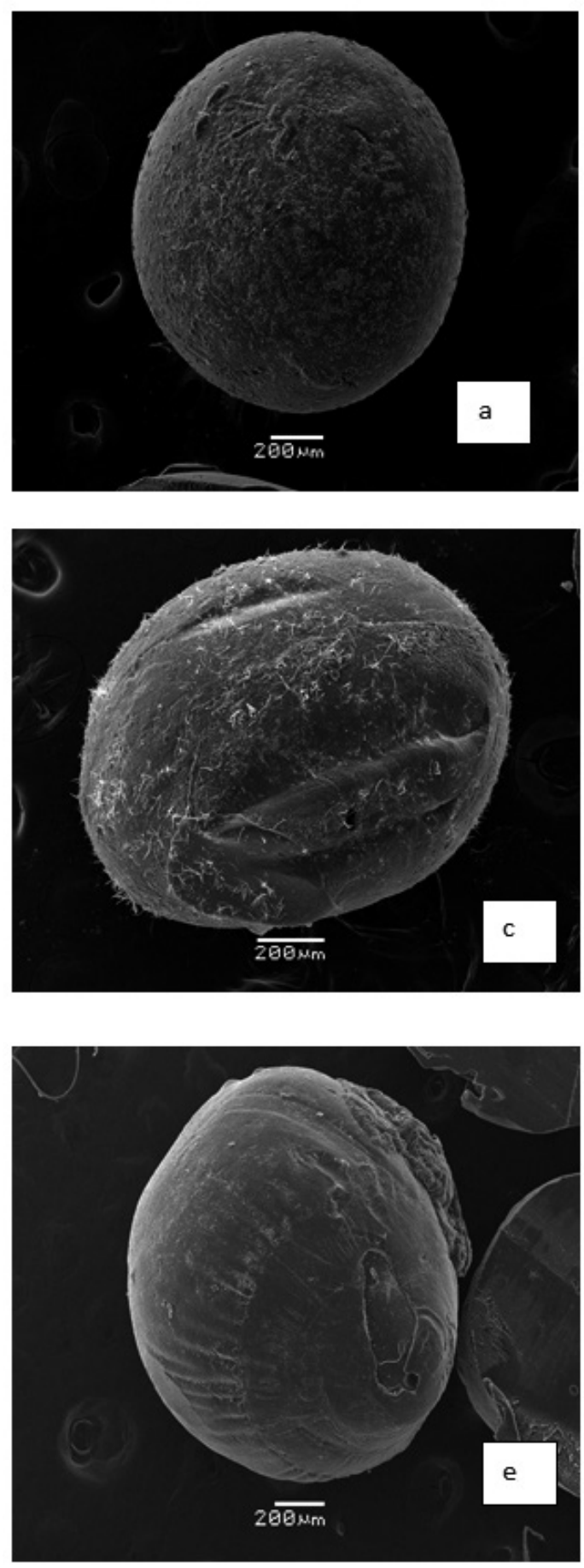

Figure 6. Micrograph for each of the beads. (a) $2 \mathrm{mg}$. (b) $3 \mathrm{mg}$. (c) $4 \mathrm{mg}$. (d) $5 \mathrm{mg}$. (e) $6 \mathrm{mg}$. (f) $7 \mathrm{mg}$.
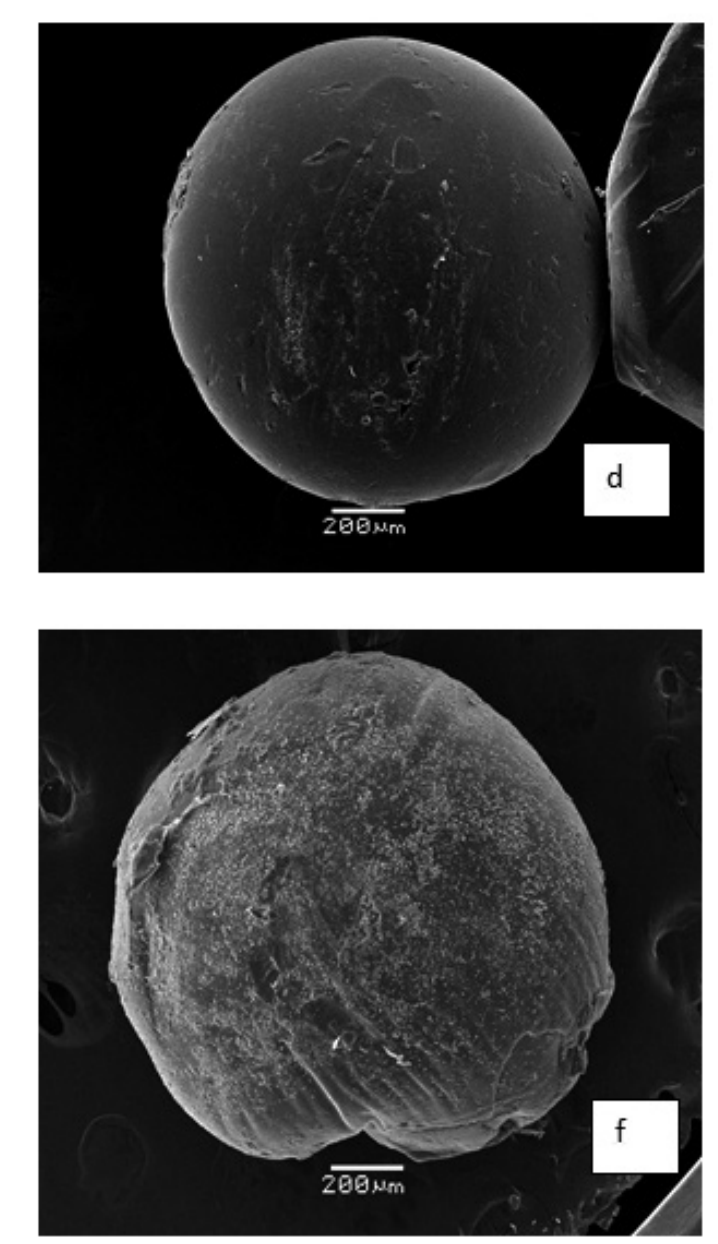

$6 \mathrm{mg}$ (6-e) and $7 \mathrm{mg}(6-\mathrm{f})$ had very irregular spherical shapes. Chitosan solution was very diluted and is difficult to sustain the form of drop since cover formation of microcapsules was slow and then stick together both into the solution and also during the drying process, therefore the spherical shape becomes irregular. The particle size of spheres were ranging from $1.22 \mathrm{~mm}$ to $1.42 \mathrm{~mm}$ diameter (figure 6-e and 6-f, respectively). The sizes of particles among microspheres with capping were homogeneous and were in the range of the $1.06-1.42 \mathrm{~mm}$ of diameter, size that only depends on the diameter of the instrument used to dribble.

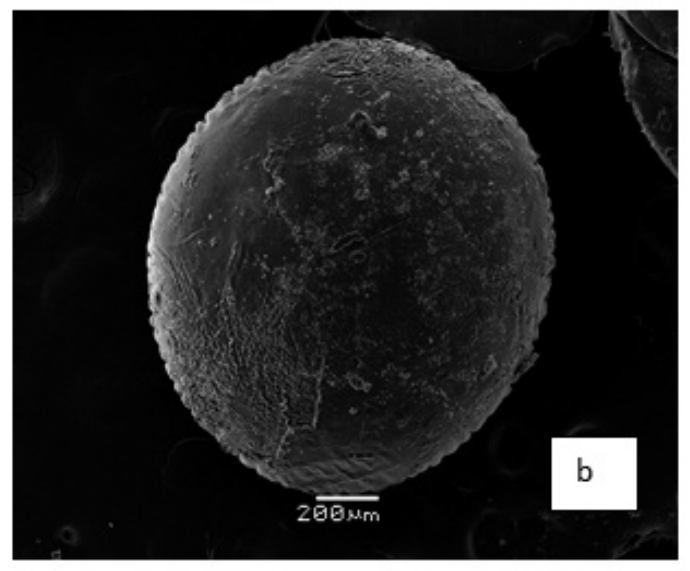


Solubility tests

The solubility of microspheres varied according to the $\mathrm{pH}$, since it was necessary the protonation of the amino groups to produce their solubility, therefore solubility in nanopure water, which is shown in table 4 . The encapsulated chitosan microspheres according to its mass of oxolinic acid sample is listed, where zero corresponds to chitosan microspheres without encapsulation, showing a low solubility, less than $1 \%$ in 15 minutes and slow stirring.

Table 4. Solubility tests of Chitosan microspheres with oxolinic acid in nanopure water.

\begin{tabular}{|c|c|c|c|c|}
\hline $\begin{array}{c}\text { Oxolinic acid } \\
\text { (mg) }\end{array}$ & I W(gr) & FW (gr) & $\begin{array}{c}\text { Mass } \\
\text { solubilized } \\
\text { (g) }\end{array}$ & $\begin{array}{c}\text { \% } \\
\text { Solubility }\end{array}$ \\
\hline $\mathbf{0}$ & 0.1076 & 0.1066 & 0.0010 & 0.9294 \\
\hline $\mathbf{2}$ & 0.1020 & 0.1010 & 0.0010 & 0.9804 \\
\hline $\mathbf{3}$ & 0.1047 & 0.1040 & 0.0007 & 0.6686 \\
\hline $\mathbf{4}$ & 0.1009 & 0.1007 & 0.0002 & 0.1982 \\
\hline $\mathbf{5}$ & 0.1008 & 0.0998 & 0.0010 & 0.9921 \\
\hline $\mathbf{6}$ & 0.1042 & 0.1040 & 0.0002 & 0.1919 \\
\hline $\mathbf{7}$ & 0,1003 & 0,1000 & 0.0003 & 0,2991 \\
\hline
\end{tabular}

$\mathrm{IW}=$ initial weight; $\mathrm{FW}=$ final weight

This low solubility showed by microspheres was due to the hydration of them, even in some cases of rupture. The microspheres solubility made by chitosan and the encapsulated ones, showed the highest solubility for sample 5 with $0.9921 \%$, and the lowest soluble mass corresponded to the sample 6 with $0.1919 \%$ solubility. The concentration of antibiotic in the areas did not affect the solubility in nanopure water. It was not trend of solubility in time [14].
Table 5. Solubility tests of Chitosan and spheres with oxolinic acid in seawater.

\begin{tabular}{|c|c|c|c|c|}
\hline $\begin{array}{c}\text { Oxolinic } \\
\text { acid (mg) }\end{array}$ & IW (gr) & FW (gr) & $\begin{array}{c}\text { Mass } \\
\text { solubilized } \\
\text { (gr). }\end{array}$ & $\begin{array}{c}\text { Solubility } \\
\text { (\%) }\end{array}$ \\
\hline $\mathbf{0}$ & 0.1055 & 0.1050 & 0.0005 & 0.47 \\
\hline $\mathbf{2}$ & 0.1088 & 0.1080 & 0.0008 & 0.74 \\
\hline $\mathbf{3}$ & 0.1007 & 0.1000 & 0.0007 & 0.70 \\
\hline $\mathbf{4}$ & 0.1033 & 0.1029 & 0.0004 & 0.39 \\
\hline $\mathbf{5}$ & 0.1025 & 0.1023 & 0.0002 & 0.20 \\
\hline $\mathbf{6}$ & 0.1010 & 0.1007 & 0.0003 & 0.30 \\
\hline $\mathbf{7}$ & 0.1074 & 0.1069 & 0.0005 & 0.47 \\
\hline
\end{tabular}

In the case of seawater ( $\mathrm{pH} 7.5$ ), solubility was low, but chitosan spheres begin to hydrate, the amino group cannot be protonated, in order to achieve its Kps and the solubility. The solubilities for each encapsulated according to their mass of oxolinic acid is shown in table 5, in addition to the initial and final weight in grams. Table 5 indicates that the solubilities were low reaching values lower than $1 \%$, where the higher solubility was shown by sample 2 with a $0.74 \%$, solubility higher than the sample 5 with a $0.20 \%$. As trials with nanopure water solubility was low and there was a marked tendency of solubility in time, therefore release of oxolinic acid in seawater did not cause a significant impact, chitosan began to hydrate and did not allow the antibiotic to diffuses easily. To observe the behavior of chitosan microspheres inside the stomach of fish, the solubility of them was determined in a $\mathrm{pH}$ range from 1 to $\mathrm{pH}$ 5.5. Table 6 shows the initial weights recorded at various $\mathrm{pH}$ for different concentrations of oxolinic acid, being zero for chitosan spheres without encapsulation. Table 6 contains the final weights recorded after the solubility test at various $\mathrm{pH}$ for each sample. The final difference among initial weights and the final weights were reported in percentage.

Table 6. Solubilities in percentages for samples of chitosan microspheres with oxolinic acid in $\mathrm{HCl}$ at different $\mathrm{pH}$.

\begin{tabular}{|c|c|c|c|c|c|c|c|}
\hline $\mathbf{p H}$ & Sample 0 & Sample 1 & Sample 2 & Sample 3 & Sample 4 & Sample 5 & Sample 6 \\
\hline $\mathbf{1}$ & 4.310 & 3.900 & 4.100 & 4.000 & 4.000 & 3.800 & 7.900 \\
\hline $\mathbf{1 . 5}$ & 12.351 & 11.178 & 10.000 & 9.100 & 8.900 & 11.100 & 10.000 \\
\hline $\mathbf{2}$ & 18.881 & 17.478 & 15.400 & 14.200 & 12.400 & 100 \\
\hline $\mathbf{2 . 5}$ & 22.908 & 19.248 & 18.700 & 17.300 & 15.500 & 13400 & 12.000 \\
\hline $\mathbf{3}$ & 24.951 & 22.500 & 20.200 & 19.400 & 17.400 & 17.300 & 13.400 \\
\hline $\mathbf{3 . 5}$ & 25.620 & 24.500 & 21.600 & 19.500 & 17.400 & 13.600 \\
\hline $\mathbf{4}$ & 24.470 & 22.222 & 20.800 & 18.800 & 17.000 & 170 \\
\hline $\mathbf{4 . 5}$ & 21.700 & 20.900 & 16.800 & 17.400 & 15.800 & 14.500 & 13.000 \\
\hline $\mathbf{5}$ & 17.600 & 16.600 & 16.500 & 14.500 & 13.600 & 12.300 & 11.400 \\
\hline $\mathbf{5 . 5}$ & 11.500 & 11.120 & 11.600 & 10.400 & 10.200 & 9.774 & 9.440 \\
\hline
\end{tabular}

The solubilities of chitosan microspheres were varied, according to the $\mathrm{pH}$ and the concentration of antibiotic in the sample, the lowest solubility was given for sample 5 at $\mathrm{pH} 1$ with a $3.85 \%$ and the highest solubility was at $\mathrm{pH}$ 3.5 with $25.62 \%$ for chitosan drug free. The solubility behavior of the spheres at different $\mathrm{pH}$ is seen more clearly in table 6 , which describes the percentage of solubility for each sample in the range of $\mathrm{pH}$ work. All cases showed a curve with Gaussian trend, where the solubility increased until optimum $\mathrm{pH} 1$ and then decreased when the $\mathrm{pH}$ was approaching to more alkaline range. The maximum solubility of chitosan spheres at $\mathrm{pH} 3.5$ was given by the ability of the protonated amino group solutions to slightly acid, thus increasing capacity microspheres, at higher $\mathrm{pH}$ hydrophilic proton availability decreases, also decreasing the solubility. In the case of lower than $3.5 \mathrm{pH}$ solubility also decreases up to $\mathrm{pH} 1$, phenomenon which is explained by the nature of hydrogels presenting microspheres of chitosan, which begin to have a maximum volume at acidic $\mathrm{pH}$, with a repulsion among charged groups, thus a minimum shielding thus generating an excess of acid. The samples solubility decreased as it increased the amount of added antibiotics for their synthesis, since high concentrations of antibiotic microspheres had concentrations of chitosan more diluted and therefore the solubility of the microspheres was also given by the solubility of the oxolinic acid which solubilizes at alkaline $\mathrm{pH}$.

Determination of oxolinic acid in chitosan microspheres.

Determination of active encapsulated for sample 6 at different concentrations within the microspheres is summarized in table 7, which shows the average area obtained by the method of HPLC applied to oxolinic acid, showing concentration in $\mu \mathrm{g} / \mathrm{ml}$ calculated for each area, this value correspond to the amount of oxolinic acid which was not encapsulated, registering the largest loss in the sample number 4 with $17.16 \mu \mathrm{g} / \mathrm{ml}$ and the lowest loss in sample 1 with a loss of $6,76 \mu \mathrm{g} / \mathrm{ml}$ concentration. It was not shown a relationship between the initial concentration of oxolinic acid added for the formation of the microcapsules and the loss of antibiotic (non-encapsulated oxolinic acid), there was no a big loss of antibiotic in high concentrations of initial oxolinic acid 
Table 7. Concentration of oxolinic acid encapsulated in microspheres according to areas obtained by HPLC, and the capacity of encapsulation (E.C.) and the effectiveness of encapsulation (E.E) in percentage.

\begin{tabular}{|c|c|c|c|c|}
\hline $\begin{array}{c}\text { Number of } \\
\text { sample }\end{array}$ & $\begin{array}{c}\text { Average } \\
\text { area }\end{array}$ & $\mathbf{C}[\boldsymbol{\mu g} / \mathbf{m l}]$ & E.C.(\%) & E.E.(\%) \\
\hline $\mathbf{1}$ & 2508922 & 6.76 & 0.16 & 93,20 \\
\hline $\mathbf{2}$ & 2633235 & 6.80 & 0.24 & 95,40 \\
\hline $\mathbf{3}$ & 2627707 & 7.08 & 0.32 & 96,46 \\
\hline $\mathbf{4}$ & 6568773 & 17.16 & 0.39 & 93,13 \\
\hline $\mathbf{5}$ & 4454544 & 11.75 & 0.48 & 96,08 \\
\hline $\mathbf{6}$ & 2485226 & 7.61 & 0.57 & 97,82 \\
\hline
\end{tabular}

The encapsulation capacity (E.C.) given in percentage indicates that highest encapsulation was presented by sample 6 with $0.57 \%$ and lowest encapsulation by sample 1 with $0.16 \%$, encapsulation ability increased as it increased the amount of oxolinic acid in initial samples. According to the values of encapsulation efficiency of antibiotic within microspheres, presented high values of encapsulation, over $93 \%$, where the highest encapsulation occurs in sample 6 with $97.8 \%$ and the lowest encapsulation in sample 4 being $93,1 \%$. There was a clear relationship between the initial concentration of oxolinic acid and encapsulation efficiency, but it could be that by increasing the initial antibiotic concentration higher efficiency is obtained, as in sample 6, where the greatest initial concentration of antibiotic is also the highest percentage of encapsulation.

The chromatograms of six samples analyzed by HPLC, shows the time of run on the abscissa and the intensity of fluorescence in the axis, and the corresponding pick of oxolinic acid that had a retention time of $5.2 \mathrm{~min}$, approximately.

\section{Extractions}

In order to estimate the amount of oxolinic acid encapsulated in a microsphere, the extractions are summarized in table 8, showing for each sample averages from the time of retention, the height and the area, in addition to its respective concentration estimated through its area. The amounts of oxolinic acid estimated for each microsphere increased as it increased the concentration of total encapsulation.

Table 8. Averages concentrations for the six samples of work in $[\mu \mathrm{g} / \mathrm{ml}]$ for one bead.

\begin{tabular}{|c|c|c|c|c|}
\hline $\begin{array}{c}\text { Number of } \\
\text { sample }\end{array}$ & $\begin{array}{c}\text { Average } \\
\text { Rt }\end{array}$ & $\begin{array}{c}\text { Average } \\
\text { height }\end{array}$ & Average area & $\begin{array}{c}\text { [ } \boldsymbol{\mu g} / \mathbf{m l}] \\
\text { average }\end{array}$ \\
\hline $\mathbf{1}$ & 5.33 & 341114 & 2185755 & 0,129 \\
\hline $\mathbf{2}$ & 5.33 & 557563 & 3349199 & 0.205 \\
\hline $\mathbf{3}$ & 5.33 & 630531 & 3494646 & 0,214 \\
\hline $\mathbf{4}$ & 5.33 & 688164 & 5037206 & 0.315 \\
\hline $\mathbf{5}$ & 5.33 & 1305638 & 7100895 & 0,449 \\
\hline $\mathbf{6}$ & 5.33 & 2703931 & 18250003 & 1,175 \\
\hline
\end{tabular}

\section{Release antibiotic tests}

The release of antibiotic within the microspheres was carried out through changes of $\mathrm{pH}$, where chitosan began to solubilize and the oxolinic acid began to spread, table 9 summarizes concentrations released at various times for 6 types of sample in test of 54 hours at $\mathrm{pH}$ 7.5. The first two hour of test, there was practically no release but then, after that time all samples began to release small amounts of antibiotic. Figure 7 shows the trend of release curves, which indicates that there is a quick release on the first day, but then the release was slower becoming constant over time.

Table 9. Release time of oxolinic acid at $\mathrm{pH}$ 7.5.

\begin{tabular}{|c|c|c|c|c|c|c|c|}
\hline \multirow{2}{*}{ Sample } & \multirow{2}{*}{ Minutes } & \multicolumn{5}{|c|}{ Number of sample } \\
\cline { 3 - 8 } & & {$[\boldsymbol{\mu} / \mathbf{m l}] \mathbf{1}$} & {$[\boldsymbol{\mu} / \mathbf{m l}] \mathbf{2}$} & {$[\boldsymbol{\mu} / \mathbf{m l}] \mathbf{3}$} & {$[\boldsymbol{\mu} / \mathbf{m l}] \mathbf{4}$} & {$[\boldsymbol{\mu} / \mathbf{m I}] \mathbf{5}$} & {$[\boldsymbol{\mu} / \mathbf{m l}] \mathbf{6}$} \\
\hline T0 & $\mathbf{0}$ & 0.000 & 0.000 & 0.000 & 0.000 & 0.000 & 0.000 \\
\hline T1 & $\mathbf{3 0}$ & 0.000 & 0.000 & 0.000 & 0.000 & 0.000 & 0.000 \\
\hline T2 & $\mathbf{6 0}$ & 0.000 & 0.000 & 0.000 & 0.000 & 0.003 & 0.000 \\
\hline T3 & $\mathbf{9 0}$ & 0.000 & 0.037 & 0.000 & 0.259 & 0.187 & 0.006 \\
\hline T4 & $\mathbf{1 2 0}$ & 0.629 & 0.690 & 0.000 & 2.157 & 3.074 & 2.336 \\
\hline T5 & $\mathbf{1 5 0}$ & 1.073 & 1.530 & 1.379 & 3.827 & 3.491 & 3.979 \\
\hline T6 & $\mathbf{1 8 0}$ & 1.465 & 4.352 & 2.862 & 4.256 & 5.466 & 4.306 \\
\hline T7 & $\mathbf{4 8 0}$ & 2.415 & 4.732 & 4.093 & 4.824 & 5.752 & 5.362 \\
\hline T8 & $\mathbf{2 7 0 0}$ & 4.600 & 5.499 & 5.748 & 6.493 & 6.804 & 6.910 \\
\hline T9 & $\mathbf{3 2 4 0}$ & 4.664 & 5.521 & 5.757 & 6.572 & 6.889 & 6.976 \\
\hline
\end{tabular}

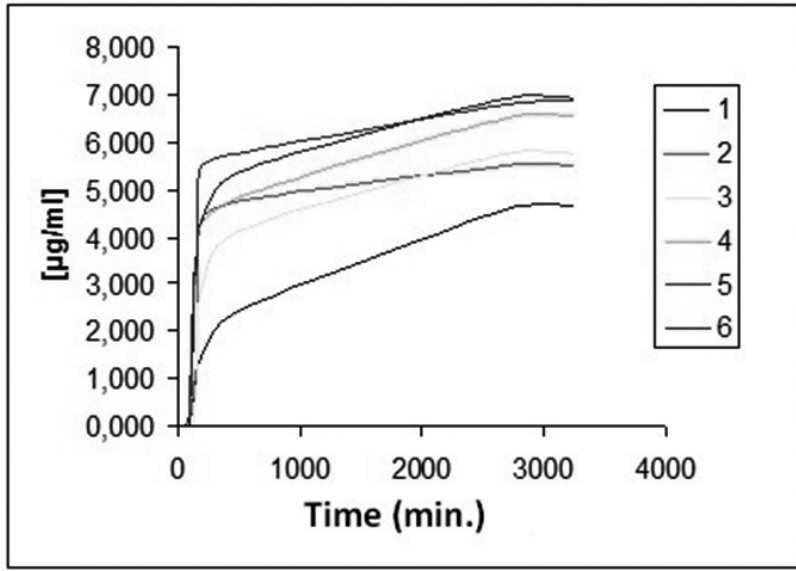

Figure 7. Release kinetics of oxolinic acid in buffer phosphate at $\mathrm{pH}$ 7.5. 
The test release at $\mathrm{pH} 5.7$ was performed in the same way as above, but for 40 hours (table 10) where the first releases were at 30 minutes after the test. Figure 8, shows the release test, where compared to $\mathrm{pH} \mathrm{7.5,} \mathrm{the} \mathrm{release}$ was nearly complete in early hours being constant in two graphs of release, there was a relationship between the concentration and the release, i.e. more oxolinic acid microspheres not freed, faster antibiotic release to areas of lower concentrations.

Table 10. Release time of oxolinic acid at $\mathrm{pH} 5.7$.

\begin{tabular}{|c|c|c|c|c|c|c|c|}
\hline Sample & Minutes & \multicolumn{5}{|c|}{ Number of sample[ $\boldsymbol{\mu g} / \mathbf{m l}]$} \\
\hline T0 & $\mathbf{0}$ & 0.000 & 0.000 & 0.000 & 0.000 & 0.000 & 0.000 \\
\hline T1 & $\mathbf{3 0}$ & 1.876 & 0.047 & 0.823 & 1.720 & 1.635 & 2.011 \\
\hline T2 & $\mathbf{6 0}$ & 1.957 & 1.894 & 0.895 & 1.723 & 1.870 & 2.106 \\
\hline T3 & $\mathbf{9 0}$ & 2.008 & 2.058 & 1.821 & 1.819 & 1.931 & 2.129 \\
\hline T4 & $\mathbf{1 2 0}$ & 2.098 & 2.133 & 1.917 & 1.903 & 1.941 & 2.266 \\
\hline T5 & $\mathbf{1 8 0}$ & 2.010 & 2.288 & 2.176 & 1,958 & 2.017 & 2.740 \\
\hline T6 & $\mathbf{2 4 0}$ & 2.228 & 2.378 & 2.336 & 1.977 & 2.067 & 2.772 \\
\hline T7 & $\mathbf{3 0 0}$ & 2.517 & 2.413 & 2.368 & 2.100 & 2.482 & 3.521 \\
\hline T8 & $\mathbf{6 0 0}$ & 2.545 & 2.573 & 2.648 & 2.998 & 3.456 & 3.778 \\
\hline T9 & $\mathbf{9 6 0}$ & 2.546 & 2.573 & 2.649 & 2.998 & 3.455 & 3.778 \\
\hline
\end{tabular}

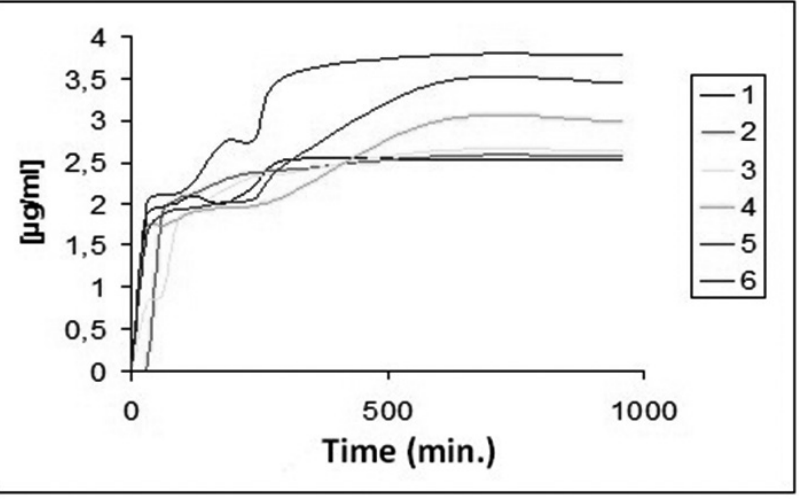
5.7 .

Figure 8. Kinetics of liberation of oxolinic acid in phosphate buffer $\mathrm{pH}$

Weight of the microspheres

Weight of microspheres was determined through a frequency histogram of sizes (Figure 9) showing the weights of microspheres in $\mathrm{mg}$ in relation to their relative frequency, which means that they were grouped within similar sizes ranges, the average of the microspheres was $0,0011 \mathrm{mg}$ with a standard deviation of 1,933

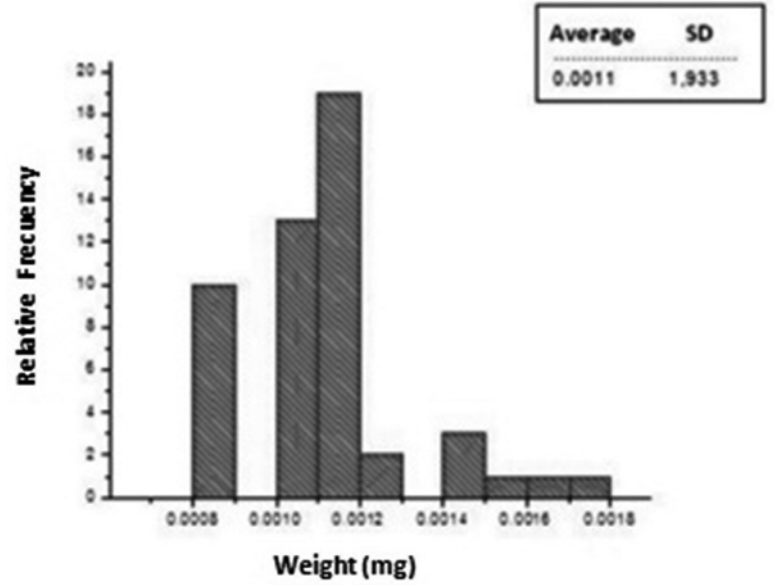

Figure 9. Histogram of frequencies in relation to weight in $\mathrm{mg}$ of microspheres. CAMBIAR EN GRAFICO.Weight (mg). Cambiar orden ordenada: Relative Frequency
Preliminary tests in fish

Four methodologies applied to perform toxicity bioassay of microspheres in fish gave negative results, to carry out bioassay, fish had to swallow the microspheres, but in any case this was not possible, since fish ate only a part of the microspheres given, and even in some cases did not eat any of them [19].

\section{CONCLUSIONS}

Chitosan used for synthesis of microspheres has a medium low molecular weight and a high degree of deacetylation, these were prepared by means of ionic gelling. The chitosan gel was obtained in presence of $\mathrm{KOH}$.

The presence of chitosan and the antibiotic was corroborated by FT-IR bands of microspheres.

Chitosan microspheres with oxolinic acid had a thermal decomposition that determined incorporation of the antibiotic in the microspheres, since peaks appeared in the first derivative which corresponded to the decomposition of the encapsulated samples at $279^{\circ} \mathrm{C}$ instead of chitosan that decomposes at $296^{\circ} \mathrm{C}$ and oxolinic acid at $324^{\circ} \mathrm{C}$.

The form of chitosan microspheres changed, that according to the concentrations of oxolinic acid, present different outward forms. This could be seen in the scanning microscopy, since as the concentration of antibiotic increased the external texture became smoother. There was a relationship between concentration of antibiotic and the internal shape of microsphere, the greater amount of antibiotic, the appearance of white granules is associated with the higher oxolinic acid concentration.

Chitosan solubility of microspheres was very low in sea water and nanopure water, since protonation of the amino group was low and chitosan less soluble.

Solubility of chitosan with different concentrations of antibiotic microspheres showed a Gaussian tendency in different ranges of $\mathrm{pH}$ to very acid $\mathrm{pH}$ (hydrogels), microspheres presented swelling and at basic $\mathrm{pH}$, protonation of the amino group was low.

The optimum $\mathrm{pH}$ of solubility of chitosan microspheres occurred at $\mathrm{pH}$ 3.5 , what was observed at the maximum point of the curve.

Chitosan microspheres had different concentrations of oxolinic acid, the release values of antibiotic concentration was quantified by HPLC method.

The encapsulation percentage of microspheres was high, all the encapsulation percentages were higher than $90 \%$.

The oxolinic acid release on chitosan microspheres was fast at $\mathrm{pH}$ 5.7, and slow at $\mathrm{pH} 7.5$.

Chitosan microspheres had an average dry weight of $0,0011 \mathrm{mg}$, as it shown by the histogram of frequencies.

\section{REFERENCES}

1. Smith P. (1999) Mechanisms of infection of bacterial pathogens in fish salmon. DIS. Aquat.Org. 37:165-172.

2. Leal J. and Woywood D. (2007) Piscirickettsiosis in Chile: advances and perspectives for its control. Salmociencia 34-42. 
3. Fryer J.L., Lannan C., Garces L.H, Larenas J.J, Smith P.A. (1990) Isolation of a rickettsia-like organism from diseased coho salmon (Oncorhynchuskisutch) in Chile, Fish Pathol. 25: 107-114.

4. Cvitanich J.D., Garate O., Smith C.E (1991) The isolation of a rickettsialike organism causing disease and mortality in Chilean salmonids and its confirmation by Koch's postulate, J. Fish Dis. 14: 121-145.

5. Larenas J., Contreras J. Smith P. (1998) Current status of Piscirickettsiosis in salmon. Revista AquaTIC5:20-26.

6. Bravo S. and M. Fields. (1989) Syndrome of the Coho Salmon. Fishing Chile 54: 47-48.

7. Igor P., Diaz I.(2006) X-ray State to the salmon industry. Report prepared by the Centro Ecoceanos. $20 \mathrm{p}$

8. Palmer M. A., R. F. Ambrose and N. L. Poff. (1997) Ecological theory and community ecology. Restoration Ecology 5(4): 291-300.

9. Gesche E., Madrid E. and Eagle C. (2001) Effect of pH, bacterial strain and type of sample, in microbiological detection, oxolinic acid and oxytetracycline in fish. Arch. Med. Vet., 33:21-29.

10. Castells M., Castells S., Hernandez M. Pharmacology in nursing. Second Edition. Elsevier publishing. 2007 Spain. 418-420.

11. Vila J. Pharmaceutical technology: Fundamentals of pharmaceutical systems and basic operations. 1997 Volume I, Chapter 10.
12. Taboada E. Cabrera G. and Cardenas G. (2002) Retention capacity of chitosan for copper and mercury ions. J. Chil. Chem. Soc. 48:7-12.

13. Taboada V., E., Cabrera B., G. and Cárdenas T, G. (2003) Synthesis and Characterization of New Arylamine Chitosan derivatives. J. Appl. Polymer Sci. 91, 807.

14. Larez C. (2003) Some applications of chitosan in aquatic systems. Iberoamerican Journal of Polymers 4: 91-109. 15.Rivas I. M Gil and Torres A. (2003) Influence of emulsifier on the characteristics of microcapsules obtained by artificial polymerization. Pharmaceutical technology 30:225228.

15. Rivas I., Gil M. and Torres A., Pharmaceutical Technology 30:225-228 (2003).

16. Peniche C, Studies on chitin and Chitosan, Doctor's Degree Thesis. La Havana Faculty of Chemical Sciences University (La Havana, 95 P.2006)

17. Burgos M, Thesis Licenciado Química, Químico-Marino, Univ. Católica Santisima Concepción, June 2009, Concepción, Chile.

18. Anaya, P., Cárdenas, G., Lavayen, V., García, A., D’Wayer, C.O. (2013) Chitosan Gel Film Bandages: Correlating Structures, Composition and Antimicrobial Properties. J. Appl. Polymer Science, 128(6), 3939-3948, 2012.DOI 101002/AP38621.

19. Heads M. (2007) Natural drugs in salmon farming: an alternative in disease control. Salmociencia 27-33. 